TITLE:

\title{
A model of reaction field in gas- injected arc-in-water method to synthesize single-walled carbon nanohorns: Influence of water temperature
}

\section{AUTHOR(S):}

Poonjarernsilp, Chantamanee; Sano, Noriaki; Tamon, Hajime; Charinpanitkul, Tawatchai

\section{CITATION:}

Poonjarernsilp, Chantamanee ... [et al]. A model of reaction field in gas-injected arc-inwater method to synthesize single-walled carbon nanohorns: Influence of water temperature. JOURNAL OF APPLIED PHYSICS 2009, 106(10): 104315.

\section{ISSUE DATE:}

2009-11

URL:

http://hdl.handle.net/2433/109889

\section{RIGHT:}

Copyright 2009 American Institute of Physics. This article may be downloaded for personal use only. Any other use requires prior permission of the author and the American Institute of Physics. The following article appeared in JOURNAL OF APPLIED PHYSICS 106, 104315 (2009) and may be found at

http://link.aip.org/link/JAPIAU/v106/i10/p104315/s1 


\title{
A model of reaction field in gas-injected arc-in-water method to synthesize single-walled carbon nanohorns: Influence of water temperature
}

\author{
Chantamanee Poonjarernsilp, ${ }^{1,2}$ Noriaki Sano, ${ }^{1, a)}$ Hajime Tamon, ${ }^{1}$ and \\ Tawatchai Charinpanitkul ${ }^{2, a)}$ \\ ${ }_{1}^{1}$ Department of Chemical Engineering, Graduate School of Engineering, Kyoto University, Kyoto 615-8510, \\ Japan \\ ${ }^{2}$ Department of Chemical Engineering, Center of Excellence in Particle Technology, Faculty of Engineering, \\ Chulalongkorn University, Patumwan, Bangkok 10330, Thailand
}

(Received 17 April 2009; accepted 7 October 2009; published online 30 November 2009)

\begin{abstract}
The method to synthesize single-walled carbon nanohorns (SWCNHs) using gas-injected arc in water (GI-AIW) has been experimentally studied. GI-AIW is known as one of the cost-effective methods to obtain SWCNHs. It was revealed that the yield of SWCNHs significantly decreases with the increase in water temperature although the purity of SWCNHs is not dependent on the temperature change. Then the model of relevant reactions in the GI-AIW system was proposed by accounting the emission of carbon vapor, formation of SWCNHs, and diffusion of water vapor in three zones inside the cathode hole (arc plasma zone, quenching zone, and downstream zone). The side reaction between $\mathrm{H}_{2} \mathrm{O}$ and $\mathrm{C}$ produces $\mathrm{H}_{2}$ gas and consumes a certain amount of carbon vapor, resulting in the hindered SWCNH formation. Moreover the observation of the optical spectra emitting from the arc plasma zone strongly supported that the $\mathrm{H}_{2}$ generating reaction does not occur at arc plasma zone since $\mathrm{N}_{2}$ flow can purge $\mathrm{H}_{2} \mathrm{O}$ out. The model proposed in this study can precisely explain the correlation between $\mathrm{H}_{2}$ gas production and water temperature. (C) 2009 American Institute of Physics. [doi:10.1063/1.3259377]
\end{abstract}

\section{INTRODUCTION}

Single-walled carbon nanohorns (SWCNHs) have been recognized as promising materials for many applications due to their unique structures and physical properties. ${ }^{1-3}$ For example, a mild oxidation on their surface brings about a drastic increase in their surface area, ${ }^{4,5}$ which can be used for gas fuel storage. ${ }^{6,7}$ Also, SWCNHs can show superior characteristics for the applications as catalyst support $^{8}$ and drug carrier. ${ }^{9}$ Since SWCNHs were synthesized by a laser ablation with a graphite target, ${ }^{10}$ several methods to produce SWCNHs have been reported to pursue low cost production. ${ }^{11-15}$ Among them, we have been trying to develop a method called gas-injected arc in water (GI-AIW). ${ }^{15-17}$ To date, arc current density, gas components, gas flow rate, and electrode motion were optimized to maximize the yield and the purity. ${ }^{16,17}$ However, water temperature, which is a factor essentially important to optimize this reaction field, has not yet been investigated. It is urgent to clarify this issue because we have recognized that water temperature affects significantly the yield of SWCNHs. Additionally, the formulation of a theoretical model of GI-AIW is currently demanded because none of the previous literature has provided a deep insight into this reaction system. Under such circumstance, this article experimentally reveals the influence of the water temperature on the production of SWCNHs. In addition, the reaction mechanism in GI-AIW is discussed based on the optical spectra from arc plasma and the analyses of gases emerging from the reaction site under varied conditions.

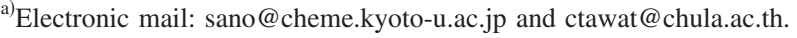

\section{EXPERIMENTAL}

The apparatus used in this study is shown in Fig. 1. Arc discharge was generated at $80 \mathrm{~A}(40 \mathrm{~V})$ between electrodes submerged in water by a dc power supply (Shindaiwa, STW200A). The anode was a graphite rod of $3 \mathrm{~mm}$ diameter and the cathode was a hollow graphite rod of $12 \mathrm{~mm}$ diameter with a large hole of $8 \mathrm{~mm}$ diameter and $25 \mathrm{~mm}$ depth on its bottom. The other side of the cathode had two narrow channels to inject $\mathrm{N}_{2}$ gas into the arc zone. $\mathrm{N}_{2}$ was supplied from a cylinder at a constant flow rate of $51 \mathrm{~min}^{-1}$. This flow rate was employed because a previous work revealed that the gas resident time with this gas flow rate leads to a preferable quenching rate of carbon vapor at $\sim 2$ $\times 10^{6} \mathrm{~K} \mathrm{~s}^{-1}$ to form SWCNHs. ${ }^{16}$ Moreover, the $\mathrm{N}_{2}$ injection was necessary to produce SWCNHs because water vapor which reacts with carbon vapor must be purged out. ${ }^{15}$ In the

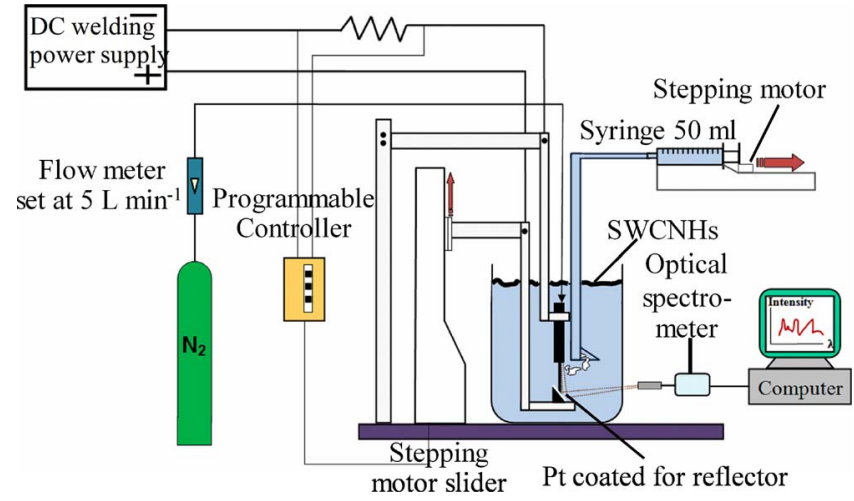

FIG. 1. (Color online) Experimental setup for synthesis of SWCNHs by GI-AIW method. 
present apparatus, the anode that was raised up toward a static cathode to keep the interelectrode gap during the anode is consumed by the arc discharge. The anode-ascending speed was controlled at $1.5 \mathrm{~mm} \mathrm{~s}^{-1}$ to continue the arc discharge for $15 \mathrm{~s}$ by a stepping motor slider (Oriental Motor, EZS3-15M). The interelectrode gap to sustain arc discharge was $\sim 0.45 \mathrm{~mm}$. To investigate the influence of water temperature, the temperatures were varied to $2,23,46,62$, and $79{ }^{\circ} \mathrm{C}$. During the arc discharge, SWCNHs were continuously produced and they floated on the water surface because of their hydrophobic behavior.

The weights of the floating SWCNHs and the consumed anode were measured to determine the yield and the production rate of SWCNHs. In our condition, energetic carbon ions colliding to the cathode surface did not cause the consumption of the cathode, but they were deposited on the cathode surface. A transmission electron microscope (TEM) (JEOL, JEM-1010) was used to characterize the morphology of SWCNHs. Raman spectroscopy (Raman Systems, R-3000) was also used to evaluate the crystallinity of the as-grown SWCNHs.

In this study, the gas emerging from the reaction producing SWCNHs was also investigated to elucidate the reaction mechanism. A glass gas-collector tube was used to collect the gas bubbles that were released from the cathode hole. The gas sampling via a glass syringe $(50 \mathrm{ml})$ was automatically started after the arc discharge was continued for $3 \mathrm{~s}$. The collected gas was analyzed by a gas chromatograph (GC) (Shimadzu, GC-14B) with a thermal conductivity detector detector using a packed column (Waters, Porapak-Q). In addition, the optical spectra of radiation from the arc plasma were recorded by an optical spectrometer (Ocean Optics, USB2000) to estimate the arc temperature and to analyze the radical formation. For this spectral analysis, a reflector coated with Pt was used to introduce the light from the arc zone to an optical fiber.

\section{RESULTS AND DISCUSSION}

\section{A. Influence of water temperature on morphology of as-grown SWCNHs}

The morphology of SWCNHs synthesized in this study can be observed in TEM images (Fig. 2). These images show that SWCNHs consisted of aggregated single-walled horns of which diameters were less than $4.6 \mathrm{~nm}$ and length was less than $17 \mathrm{~nm}$. In comparison between typical TEM images of the as-grown SWCNHs obtained from a low-temperature condition $\left(2^{\circ} \mathrm{C}\right)$ and a high-temperature condition $\left(79^{\circ} \mathrm{C}\right)$, no significant difference was observed. In both cases, the purity of SWCNHs was $\sim 70 \%$ according to our TEM observation. Amorphous carbon was observed as impurities. In addition, Raman spectroscopy was also used to evaluate the crystallinity of the as-grown SWCNHs. An inset in Fig. 3 shows a typical Raman spectrum of SWCNHs synthesized at $2{ }^{\circ} \mathrm{C}$. It is obvious that there are two peaks: graphite band $\left(G\right.$-peak) at $1580 \mathrm{~cm}^{-1}$ and disorder band ( $D$-peak) at $1330 \mathrm{~cm}^{-1}$ of which intensities are almost comparative. Such balance in the intensities of these $G$ - and $D$-peaks is common in as-grown SWCNHs. ${ }^{13-15}$ The dependence of

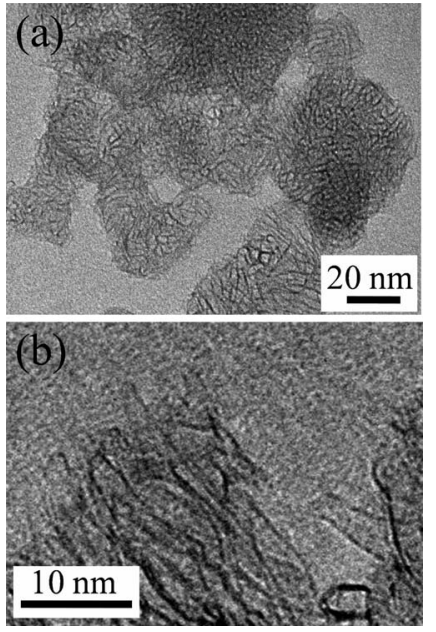

FIG. 2. Typical TEM images of SWCNHs produced by GI-AIW. (a) Low magnification image. (b) High magnification image.

$G / D$ ratio on the temperature of water is depicted in Fig. 3 to show a tendency in the crystallinity of the as-grown SWCNHs obtained at different conditions. In general, when the $G / D$ ratio is higher, the concentration of crystalline carbon nanostructures would become higher. Because amorphous impurities were contained in our as-grown SWCNHs, the higher $G / D$ ratio may indicate the higher purity. Based on our Raman investigation, it is worthy to notice that the $G / D$ ratio is hardly affected by the temperature of water. As a result, the purity of SWCNHs would reasonably be independent of the water temperature. This tendency is also consistent with the result obtained by the TEM analysis.

\section{B. Influence of water temperature on production of SWCNHs and by-product gases}

Figures 4(a) and 4(b) show the yield and the production rate of SWCNHs. The yield is defined as the ratio of the weight of as-grown SWCNHs to the total weight loss of the consumed anode in each batch of the arc discharge process. The yield and the production rate of SWCNHs tend to sig-

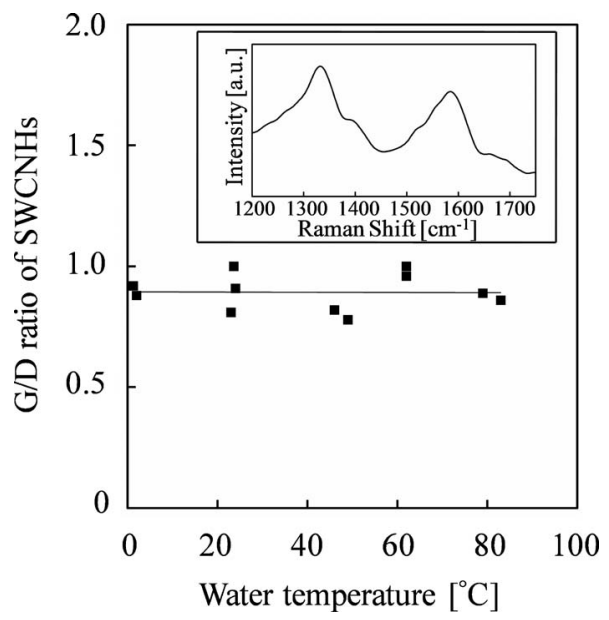

FIG. 3. Influence of water temperature on the $G / D$ ratio in Raman spectra from as-grown SWCNHs synthesized by GI-AIW with varied water temperature. Inset shows a Raman spectrum from the product at the water temperature of $2{ }^{\circ} \mathrm{C}$. 


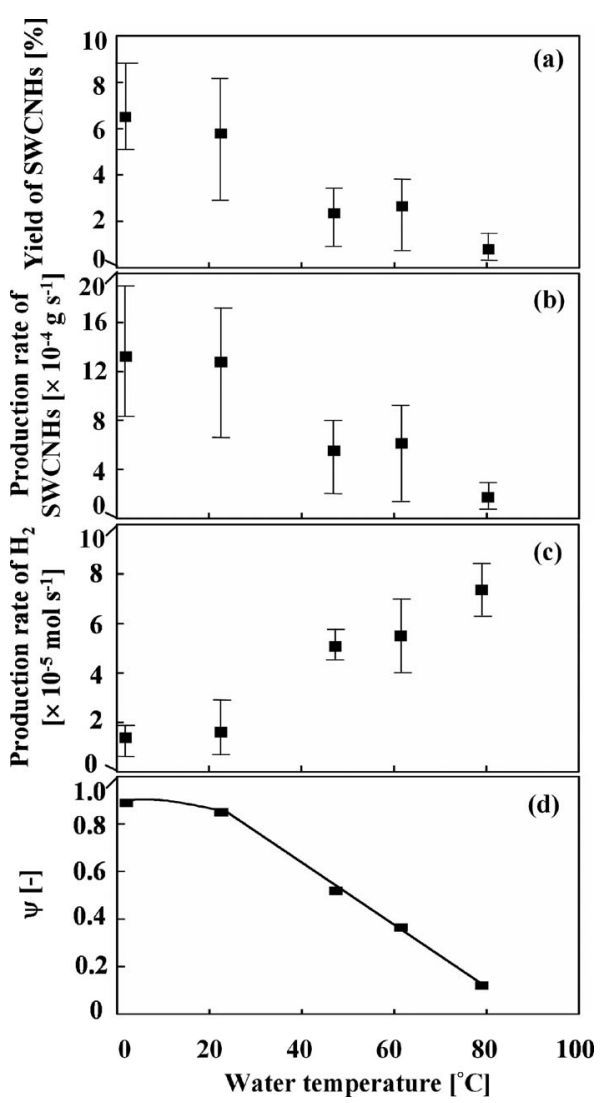

FIG. 4. Influence of water temperature on (a) the yield of SWCNHs, (b) the production rate of SWCNHs, (c) the production rate of hydrogen, and (d) the selectivity of SWCNH formation $(\psi)$.

nificantly decrease with an increase in the water temperature, in which both yield and production rate can become approximately one-eighth when the water temperature is elevated from 2 to $79{ }^{\circ} \mathrm{C}$. Meanwhile, in the gas analyses, emergence of $\mathrm{H}_{2}$ gas was also confirmed as explained later. This $\mathrm{H}_{2}$ production could be ascribed to the reaction between carbon vapor and water vapor. Although $\mathrm{N}_{2}$ was introduced to purge water vapor out from the reaction zone in GI-AIW, a certain amount of water vapor could diffuse into this zone, resulting in the inhibiting effect on the SWCNH formation. The potential reaction mechanism is proposed in Eqs. (1) and (2).

$$
\begin{aligned}
& \mathrm{C} \rightarrow \frac{1}{m} \text { SWCNHs, } \\
& \mathrm{C}+\mathrm{H}_{2} \mathrm{O} \rightarrow \mathrm{CO}+\mathrm{H}_{2},
\end{aligned}
$$

where $m$ means the number of carbon in SWCNHs.

To verify this mechanism, the formation of gaseous products was analyzed using the GC. Based on the precision of our GC, we intentionally selected the analytical condition to raise detecting sensitivity for $\mathrm{H}_{2}$. It should be noted that a single mole of $\mathrm{CO}$ formed by Eq. (2) corresponds to a single mole of $\mathrm{H}_{2}$. In fact, the $\mathrm{CO}$ production rate was slightly lower than the $\mathrm{H}_{2}$ rate in our analysis, which was close to this stoichiometrical relationship. The gap in the production rates of $\mathrm{CO}$ and $\mathrm{H}_{2}$ is attributed to the formation of other by-products, which was not detectable by our GC. Furthermore, we confirmed that $\mathrm{O}_{2}$ was not produced by arc dis- charge in water. As a result, $\mathrm{H}_{2}$ should not be generated by electrolysis of water, but mainly from Eq. (2). Then the $\mathrm{H}_{2}$ production rate was plotted against the water temperature, as shown in Fig. 4(c). The $\mathrm{H}_{2}$ production rate was determined from the gas flow rate multiplied by $\mathrm{H}_{2}$ concentration obtained from the gas chromatographic analyses. The $\mathrm{H}_{2}$ production rate was enhanced from approximately 1.5 to $7 \mathrm{~mol} \mathrm{~s}^{-1}$ when the water temperature was increased from 2 to $79{ }^{\circ} \mathrm{C}$.

For comparison, the $\mathrm{H}_{2}$ production rate in the conventional system of arc in water (AIW) ${ }^{18,19}$ without $\mathrm{N}_{2}$ injection was also determined to evaluate the effect of the $\mathrm{N}_{2}$ injection. It should be noted that the conventional AIW cannot provide SWCNHs due to the dominating Eq. (2). In the AIW system, the $\mathrm{H}_{2}$ production rate was as high as 1.02 $\times 10^{-3} \mathrm{~mol} \mathrm{~s}^{-1}$. However, the $\mathrm{H}_{2}$ production rate in the GIAIW system with low-temperature water $\left(2{ }^{\circ} \mathrm{C}\right)$ was two orders of magnitude lower than in the conventional AIW. With an increase in the water temperature to $79{ }^{\circ} \mathrm{C}$, the $\mathrm{H}_{2}$ production rate in GI-AIW became up to approximately $7 \%$ of that in AIW. This result indicates that $\mathrm{N}_{2}$ injection can effectively prevent the diffusion of water vapor into the SWCNH-producing zone. Without $\mathrm{N}_{2}$ injection, the emergence of water vapor should result in the drastic decrease in the yield of SWCNHs.

Figure 4(d) shows the selectivity of the SWCNH formation in Eq. (1) according to products including gaseous byproducts in Eq. (2). The selectivity shown in this figure is defined by

$$
\psi=\frac{r_{\mathrm{CNH}}}{r_{\mathrm{CNH}}+r_{\mathrm{H}_{2}}},
$$

where $\psi, r_{\mathrm{CNH}}$, and $r_{\mathrm{H}_{2}}$ are the selectivity for SWCNH production, the molar production rate of SWCNHs, and that of $\mathrm{H}_{2}$, respectively. The molar production rate of SWCNHs is calculated in $\mathrm{C}$ basis by dividing the gram production rate by the molecular weight of C. It can be observed that the selectivity of SWCNH production was hindered when the water temperature was increased. This is attributed to the increase in water vapor penetrating into the reaction zone due to the increased water temperature.

\section{Analyses on optical spectra from arc plasma zone}

The radical formation in arc plasma and the temperature there were investigated by analyzing its optical spectra. Figure 5 shows the typical optical spectra obtained from three conditions: (1) GI-AIW with a low water temperature at $2{ }^{\circ} \mathrm{C}$, (2) GI-AIW with a high water temperature at $70{ }^{\circ} \mathrm{C}$, and (3) conventional AIW at ambient temperature. In all cases, a peak at $516 \mathrm{~nm}$ may indicate the existence of $\mathrm{C}_{2}$ radical. ${ }^{20}$ In the conventional AIW, an outstanding peak at $660 \mathrm{~nm}$ would indicate the $\mathrm{H}$-radical $(\mathrm{H} \alpha)$ formation. ${ }^{20,21}$ However, such H-radical peak cannot be observed in both cases of GI-AIW. This result suggests that $\mathrm{H}_{2}$ production can be significantly hindered in the arc plasma zone of GI-AIW systems since $\mathrm{N}_{2}$ flow could effectively purge $\mathrm{H}_{2} \mathrm{O}$ out from the arc plasma zone. As mentioned above, $\mathrm{H}_{2}$ was generated from $\mathrm{H}_{2} \mathrm{O}$ inside the cathode hole, where SWCNHs were 


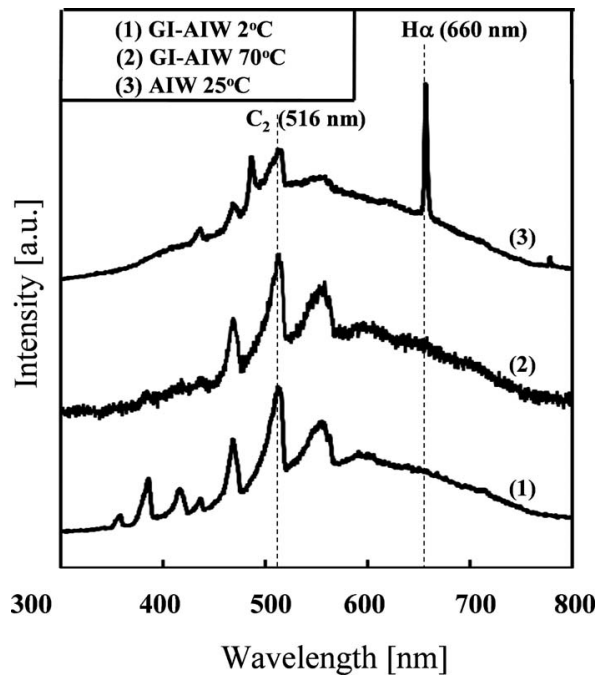

FIG. 5. Optical spectra from arc plasma in conventional AIW and GI-AIW: (1) GI-AIW at a water temperature of $2{ }^{\circ} \mathrm{C}$, (2) GI-AIW at a water temperature of $70^{\circ} \mathrm{C}$, and (3) AIW at a water temperature of $25^{\circ} \mathrm{C}$.

also produced. Here it should be noted that Eq. (2) could possibly take place outside the arc plasma zone, but at a SWCNH-producing zone.

Based on the previous discussion, we propose a schematic diagram for illustrating three zones [(1) arc plasma zone, (2) quenching zone, and (3) downstream zone] which would reasonably exist in the cathode in the GI-AIW system, as shown in Fig. 6. In this figure, the profiles of the temperature and the pressure of water vapor are also shown as a simple model. The arc plasma zone plays a role to generate carbon vapor. The quenching zone leads to the conversion of carbon vapor to SWCNHs. In the downstream zone, water vapor is generated at the liquid-gas interface, resulting in the diffusion of the water vapor toward the quenching zone. However, with sufficient flow of $\mathrm{N}_{2}$ injection, the water vapor cannot reach the arc plasma zone so that the H-radical peak is not seen in the optical spectra of the arc plasma in GI-AIW. Thus, it may be reasonable that Eq. (2) would take place at the bottom of the quenching zone.

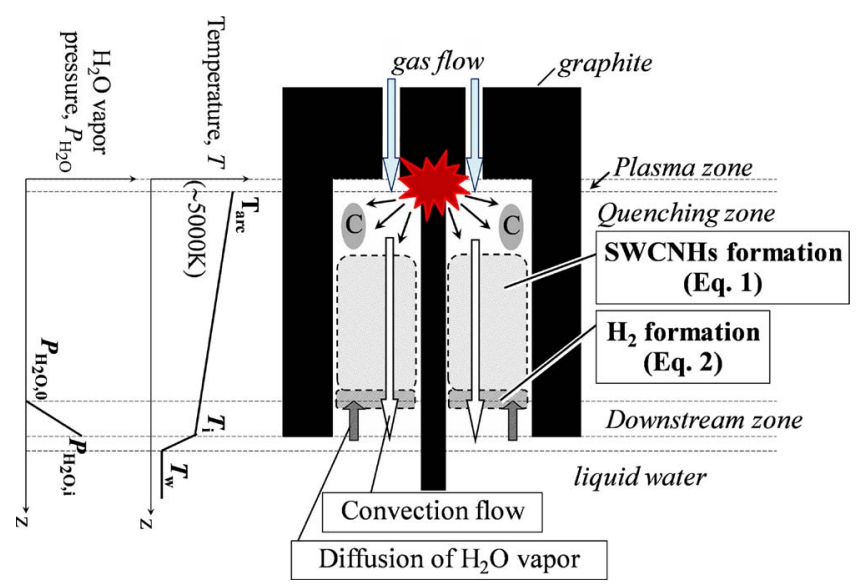

FIG. 6. (Color online) Model of the reaction field in GI-AIW with three categorized zones and schematic image of the profiles of temperature and water vapor pressure in the reaction field in the GI-AIW system.
In this study, the radiation equations known as Planck distribution law and Wien's displacement law, written in Eqs. (4) and (5), respectively, are used to determine the temperature of the arc plasma from its optical spectra.

$$
\begin{aligned}
& q_{\lambda}=2 \pi \mathrm{c}^{2} \mathrm{~h} \lambda^{-5}\left(\mathrm{e}^{\mathrm{ch} / \lambda \kappa T}-1\right)^{-1}, \\
& \lambda_{\max } T=0.2884 \mathrm{~cm} \mathrm{~K},
\end{aligned}
$$

where $q_{\lambda}, T, \lambda, \lambda_{\max }, \mathrm{c}, \mathrm{h}$, and $\kappa$ are the energy flux of light at a wavelength, temperature, wavelength, wavelength at a maximum radiation, speed of light, Planck's constant, and Boltzmann's constant, respectively.

As a result, the temperature at the arc plasma zone is estimated to be approximately $5000 \mathrm{~K}$ at all conditions used in this study. Such high temperature would be responsible for vaporization of carbon anode, leading to emergence of carbon vapor which is essential for carbon nanostructure formation.

\section{Model of water vapor diffusion and hydrogen production}

In a previous literature, a simple model was proposed to estimate the quenching rate of carbon vapor to produce SWCNHs. ${ }^{16}$ At that time, the temperature at the liquid-gas interface was assumed to be the boiling point of water regardless of bulk water temperature. However, this assumption is insufficient for describing the results observed in this study, in which the yield of SWCNHs and $\mathrm{H}_{2}$ production rate are significantly dependent on the water temperature. To explain the present results, the temperature at the liquid-gas interface at the lower end of the cathode hole must reasonably depend on the water temperature.

In this study, we modify the model, considering the temperature profile in the narrow zone adjacent to the liquid-gas interface in liquid phase. Here, the heat flux from the arc plasma zone to the liquid-gas interface and the heat flux from this interface to the bulk water are described by the heat transfer coefficient multiplied by relevant temperature difference as driving force. These heat transfers are described by Eqs. (6) and (7).

$$
\begin{aligned}
& Q_{\mathrm{g}}=k_{\mathrm{g}}\left(T_{\mathrm{arc}}-T_{\mathrm{i}}\right)+v_{\mathrm{i}} A M_{\mathrm{g}} C_{\mathrm{vg}} T_{\mathrm{i}}, \\
& Q_{\mathrm{w}}=k_{\mathrm{w}}\left(T_{\mathrm{i}}-T_{\mathrm{w}}\right)+v_{\mathrm{i}} A M_{\mathrm{w}} C_{\mathrm{vw}} T_{\mathrm{i}} .
\end{aligned}
$$

$Q, k, T, v, A, M$, and $C_{\mathrm{v}}$ are the heat flux $\left(\mathrm{J} \mathrm{m}^{-2} \mathrm{~s}^{-1}\right)$, heat transfer coefficient $\left(\mathrm{J} \mathrm{m}^{-2} \mathrm{~s}^{-1} \mathrm{~K}^{-1}\right)$, temperature $(\mathrm{K})$, velocity of gas or water at the interface to the axial direction $\left(\mathrm{m} \mathrm{s}^{-1}\right)$, area of the interelectrode space $\left(\mathrm{m}^{2}\right)$, mole density $\left(\mathrm{mol} \mathrm{m}^{-3}\right)$, and heat capacity $\left(\mathrm{J} \mathrm{mol}^{-1}\right)$, respectively. The subscripts $\mathrm{g}, \mathrm{w}$, arc, and i mean gas phase, liquid phase, arc plasma zone, and liquid-gas interface, respectively. The terms including $v_{\mathrm{i}}$ represent the effect by convection. $T_{\text {arc }}$ in our condition is approximately $5000 \mathrm{~K}$, as discussed in Sec. III C. In fact, the liquid-gas interface fluctuates due to gas flow. Nevertheless, the location of this interface is assumed to be averagely constant for the simplified steady state approximation in this study. If the steady state condition is applied, $Q_{\mathrm{g}}$ must be equal to $Q_{\mathrm{w}}$. 
When the bulk water temperature reaches the boiling point, the temperature of the liquid-gas interface should also be equivalent to the boiling point $T_{\mathrm{b}}$. Thus, a boundary condition there can be considered as Eq. (8).

$$
T_{\mathrm{i}}=T_{\mathrm{w}} \quad \text { when } T_{\mathrm{w}}=T_{\mathrm{b}} .
$$

From the relationship $Q_{\mathrm{g}}=Q_{\mathrm{w}}$ with Eq. (8), Eq. (9) can be derived.

$$
T_{\mathrm{i}}=a+T_{\mathrm{w}}\left(T_{\mathrm{b}}-a\right) / T_{\mathrm{b}},
$$

where $a$ is a complex of parameters

$$
a=k_{\mathrm{g}} T_{\text {arc }} /\left[k_{\mathrm{w}}+k_{\mathrm{g}}+v_{\mathrm{i}} A\left(-M_{\mathrm{g}} C_{\mathrm{vg}}+M_{\mathrm{w}} C_{\mathrm{vw}}\right)\right] .
$$

The mass transfer rate of $\mathrm{H}_{2} \mathrm{O}$ in the direction from the liquid-gas interface toward the quenching zone through the downstream zone can be written as

$$
\begin{aligned}
N_{\mathrm{H}_{2} \mathrm{O}}= & K_{\mathrm{p}} A\left(P_{\mathrm{H}_{2} \mathrm{O}, \mathrm{i}}-P_{\mathrm{H}_{2} \mathrm{O}, 0}\right)-\left(A v_{0} P_{\mathrm{H}_{2} \mathrm{O}, 0} / \mathrm{R} T_{0}\right. \\
& \left.+A v_{\mathrm{i}} P_{\mathrm{H}_{2} \mathrm{O}, \mathrm{i}} / \mathrm{R} T_{\mathrm{i}}\right) / 2 .
\end{aligned}
$$

$N_{\mathrm{H}_{2} \mathrm{O}}, K_{\mathrm{p}}, P_{\mathrm{H}_{2} \mathrm{O}, \mathrm{i}}$, and $P_{\mathrm{H}_{2} \mathrm{O}, 0}$ are the $\mathrm{H}_{2} \mathrm{O}$ mass transfer rate, mass transfer coefficient, $\mathrm{H}_{2} \mathrm{O}$ partial pressure at the liquidgas interface, and $\mathrm{H}_{2} \mathrm{O}$ partial pressure at the bottom of the quenching zone, respectively. The term including $K_{\mathrm{p}}$ represents the diffusion effect with a driving force, $P_{\mathrm{H}_{2} \mathrm{O}, \mathrm{i}}$ $-P_{\mathrm{H}_{2} \mathrm{O}, 0}$. The terms including $v_{0}$ and $v_{\mathrm{i}}$ represent the average $\mathrm{H}_{2} \mathrm{O}$ transfer rate caused by the convection flow.

When $\mathrm{H}_{2}$ is produced, $\mathrm{H}_{2} \mathrm{O}$ vapor must be supplied from the liquid-gas interface to the bottom of the quenching zone, where $\mathrm{H}_{2}$ is produced. From Eq. (2), the $\mathrm{H}_{2}$ production rate $r_{\mathrm{H}_{2}}$ is stoichiometrically equivalent to the mass transfer rate of $\mathrm{H}_{2} \mathrm{O}$, as described in Eq. (12).

$$
r_{\mathrm{H}_{2}}=N_{\mathrm{H}_{2} \mathrm{O}} \cdot
$$

Here, we assume that the reaction of Eq. (2) is instantaneously fast so that the partial pressure of $\mathrm{H}_{2} \mathrm{O}$ at the bottom of the quenching zone can be approximated to be zero [Eq. (13)].

$$
P_{\mathrm{H}_{2} \mathrm{O}, 0}=0 .
$$

Because the partial pressure of $\mathrm{H}_{2} \mathrm{O}$ can be estimated by Antoine equation, $P_{\mathrm{H}_{2} \mathrm{O}, \mathrm{i}}(\mathrm{Pa})$ can be written as

$$
P_{\mathrm{H}_{2} \mathrm{O}, \mathrm{i}}=\left(\frac{1.013 \times 10^{6}}{760}\right) 10^{x-y /\left(T_{\mathrm{i}}-273+z\right)},
$$

where $x=7.96681, y=1668.21$, and $z=228$, as reported in Ref. 22. Summarizing all the equations above, the partial pressure of $\mathrm{H}_{2} \mathrm{O}$ at the liquid-gas interface and the $\mathrm{H}_{2}$ production rate can be described as Eqs. (15) and (16).

$$
\begin{aligned}
& P_{\mathrm{H}_{2} \mathrm{O}, \mathrm{i}}=\left(\frac{1.013 \times 10^{6}}{760}\right) 10^{x-y /\left(a+T_{\mathrm{w}}\left(T_{\mathrm{b}}-a\right) / T_{\mathrm{b}}-273+z\right)}, \\
& r_{\mathrm{H}_{2}}=\left(K_{\mathrm{p}} A-v_{\mathrm{i}} A / 2 \mathrm{R} T_{\mathrm{i}}\right) P_{\mathrm{H}_{2} \mathrm{O}, \mathrm{i}} .
\end{aligned}
$$

In Eq. (16), $v_{\mathrm{i}} A / \mathrm{R} T_{\mathrm{i}}$ is equivalent to the mass flow rate divided by the total pressure $\left(\mathrm{mol} \mathrm{s}^{-1} \mathrm{~Pa}^{-1}\right)$ based on the ideal gas assumption $(P V=n \mathrm{R} T)$. In the present study, the total pressure in the gas stream can be considered to be nearly

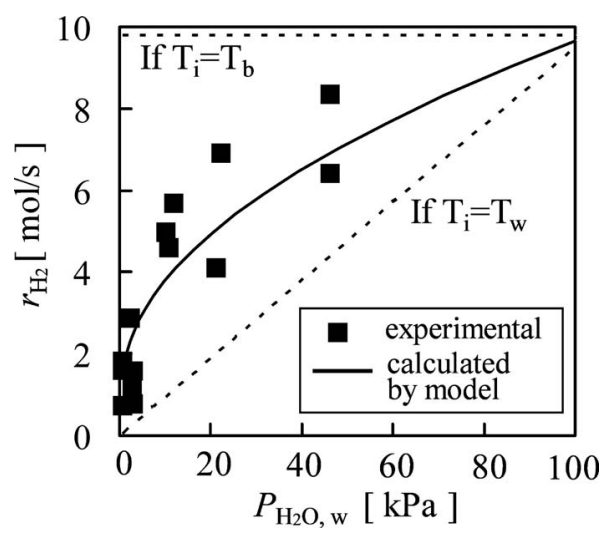

FIG. 7. Relationship between $\mathrm{H}_{2}$ production rate and the water vapor pressure directly estimated from bulk water temperature.

constant at atmospheric pressure, and the mass flow rate of $\mathrm{N}_{2}$ was also constant $\left(0.00347 \mathrm{~mol} \mathrm{~s}^{-1}\right)$. Thus, the value of $v_{\mathrm{i}} A / \mathrm{R} T_{\mathrm{i}}$ is determined as $3.4 \times 10^{-8} \mathrm{~mol} \mathrm{~s}^{-1} \mathrm{~Pa}^{-1}$.

$T_{\mathrm{i}}$ and $P_{\mathrm{H}_{2} \mathrm{O}, \mathrm{i}}$ at each $T_{\mathrm{w}}$ can be estimated after two parameters $\left(a\right.$ and $\left.K_{\mathrm{p}}\right)$ are determined by fitting the calculated $r_{\mathrm{H}_{2}}$ with the experimental values. Here, $a$ and $K_{\mathrm{p}}$ are determined as 55 and $2.2 \mathrm{~mol} \mathrm{~m}^{-2} \mathrm{~s}^{-1} \mathrm{~K}^{-1}$, respectively. Figure 7 shows the calculated relationship between $r_{\mathrm{H}_{2}}$ and $P_{\mathrm{H}_{2} \mathrm{O}, \mathrm{w}}$, which can show a characteristic of $r_{\mathrm{H}_{2}} \cdot P_{\mathrm{H}_{2} \mathrm{O} \text {,w }}$ here means the vapor pressure of $\mathrm{H}_{2} \mathrm{O}$ directly estimated from bulk water temperature, which can be calculated by substituting $T_{\mathrm{i}}$ by $T_{\mathrm{w}}$ in Eq. (14). In this figure, a calculated convex curve compared with the experimental values indicates that the present model can correlate the experimental results fairly well. Once $T_{\mathrm{i}}$ is considered as $T_{\mathrm{b}}$ as assumed in our previous model in Ref. 16, $r_{\mathrm{H}_{2}}$ becomes constant at $9.8 \mathrm{~mol} \mathrm{~s}^{-1}$, which is not consistent with the present experimental values. Alternatively, if $T_{\mathrm{i}}$ is considered as $T_{\mathrm{w}}$, the tendency in the increase in $r_{\mathrm{H}_{2}}$ seems linear, leading to an inconsistent result according to the experimental values.

Based on our newly proposed model, it can be observed in Fig. 8 that $T_{\mathrm{i}}$ is higher than $T_{\mathrm{w}}$ in all conditions used in our experiments $\left(T_{\mathrm{w}}=2-79^{\circ} \mathrm{C}\right)$. Therefore, the vapor pressure of $\mathrm{H}_{2} \mathrm{O}$ at the liquid-gas interface, $P_{\mathrm{H}_{2} \mathrm{O}, \mathrm{i}}$, is obviously higher than the vapor pressure estimated directly from water temperature, $P_{\mathrm{H}_{2} \mathrm{O}, \mathrm{w}}$. This figure also shows the well fitting of the calculated $r_{\mathrm{H}_{2}}$ with experimental values. As a result, it is reasonable that the proposed model can predict the effect of water temperature on the increasing vapor pressure of water diffusing into the GI-AIW system, causing the hydrogen production which will in turn hinder the formation of SWCNHs.

It should be recognized that the position of the interface between the quenching zone and the downstream zone can be considered to be changeable depending on the water temperature. When the water temperature is high, the downstream zone that contains $\mathrm{H}_{2} \mathrm{O}$ diffusion becomes larger, resulting in the position of this interface that is shifted upward. When this shift occurs, the quenching zone will shrink. This is why the production of SWCNHs is retarded with the elevation of water temperature in the present model. In the mathematical equations, the position of this interface is not apparently shown. However, this effect is included in the 


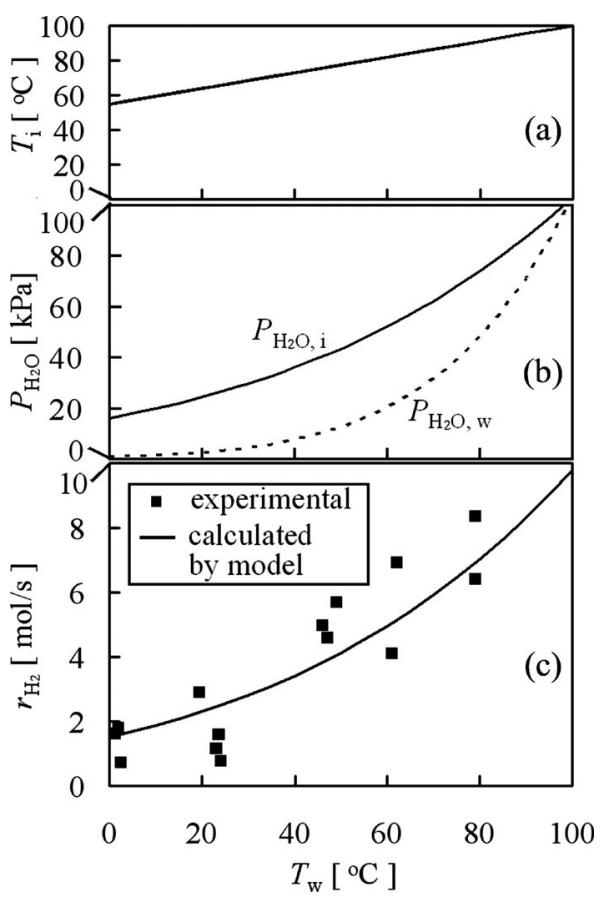

FIG. 8. Influence of water temperature on (a) temperature at the liquid-gas interface $\left(T_{\mathrm{i}}\right),(\mathrm{b})$ water vapor pressure at the liquid-gas interface $\left(P_{\mathrm{H}_{2} \mathrm{O}, \mathrm{i}}\right)$ and water vapor pressure at the bulk water temperature $\left(P_{\mathrm{H}_{2} \mathrm{O}, \mathrm{w}}\right)$, and $(\mathrm{c}) \mathrm{H}_{2}$ production rate $\left(r_{\mathrm{H}_{2}}\right)$.

parameter fitting work, as the mass transfer coefficient $K_{\mathrm{p}}$ and the heat transfer coefficients $k_{\mathrm{g}}$ and $k_{\mathrm{w}}$ should be dependent on the length of the downstream zone.

To improve the model, one may want to consider the mass balance of carbon vapor and $\mathrm{H}_{2} \mathrm{O}$ in each reaction zone. For this consideration, the concentration profile of carbon vapor should be discussed. At the present stage, this aspect is not included in the model. However, there is an information that gives a hint to consider this problem. In our previous article, ${ }^{15}$ it is reported that the yield of bulky deposit containing multiwalled carbon nanotubes is about oneorder magnitude higher than that of SWCNHs. Such deposit can attach to the surface of the cathode hole in the plasma zone or sink down to the bottom of the water container after it is peeled off. (It should be noted that such deposit is separated from the powdery SWCNHs floating on the water surface.) From the location of this deposit, it is reasonable that the concentration of carbon vapor in the plasma zone is dominantly higher than in the quenching and the downstream zones. Even if the concentration of carbon vapor in the plasma zone is very high, the carbon vapor there will not contribute to the formation of SWCNHs because the production of SWCNHs in this deposit is observed as negligible, and most of the carbon vapor in the plasma zone should be used to produce the MWCNT-including deposit. From the comparison between the production rate of SWCNHs and that of $\mathrm{H}_{2}$ in Fig. 4, their molar production rates seem to be comparable averagely. [In this calculation, the molar production rate of SWCNHs in carbon basis is derived by dividing its mass production rate $\left(\mathrm{g} \mathrm{s}^{-1}\right)$ by the molar weight of carbon (12.01 $\left.\mathrm{g} \mathrm{mol}^{-1}\right)$.] From this comparison, mean molar concentrations of carbon precursor and $\mathrm{H}_{2} \mathrm{O}$ in the SWCNH- producing zones including the quenching zone and the downstream zone can be considered as comparable.

The detailed mechanisms of the SWCNH formation and the effects of the water vapor have not yet been clarified even though the simplified model in the reaction field is established in this study. Nevertheless, we consider a hypothesis that SWCNHs may be formed from bubbled carbon droplets generated from carbon vapor. It should be noted that the round shape of ordinal bubble is stable, but the round shape of carbon bubble is not stable because the graphene sheet cannot be round without adding many defects. Instead, horn or tube shape can be stable, and thus quenched carbon bubbles may become agglomerated horn shape in selfassembling way. In this way, horns are formed from the inside of carbon droplets by boiling. On the other hand, water vapor may destroy the SWCNHs by encroaching from the outside. Thus, the structure of SWCNHs may remain even if SWCNHs are decreased by the reaction of water vapor. However, it should be recognized that there is a limiting value of water vapor concentration to preserve SWCNHs. If the water vapor concentration is excessively high as observed in the conventional AIW, SWCNHs cannot be formed as mentioned above.

\section{CONCLUSIONS}

The influence of the water temperature on the synthesis of SWCNHs by GI-AIW was experimentally investigated together with the analyses of gas production and the optical spectra from the arc plasma. The improved model of the relevant reaction mechanism was proposed by taking into account the diffusion of water vapor in the cathode hole in the GI-AIW system. It was observed that the yield and the production rate of SWCNHs were significantly decreased with the increase in water temperature although the purity of as-grown SWCNHs was independent of the water temperature. This result is ascribed to the reaction between carbon vapor and water vapor in a zone around the interface between the so-called quenching zone and the downstream zone inside the cathode hole. The present model can acceptably correlate the relationship between $\mathrm{H}_{2}$ gas production and water temperature, which can affect the SWCNH formation.

\section{ACKNOWLEDGMENTS}

This work is financially supported by the Commission of Higher Education of Thailand (CHE), Japan Society for the Promotion of Science (JSPS) Grant-in-Aid for Exploratory Research (Contract No. 19656024) and Scientific Research B (Contract No. 21360394), and the Centennial Fund of CU.

${ }^{1}$ S. Garaj, L. Thien-Nga, R. Gaal, L. Forro, K. Takahashi, F. Kokai, M. Yudasaka, and S. Iijima, Phys. Rev. B 62, 17115 (2000).

${ }^{2}$ S. Berber, Y. K. Kwon, and D. Tomanek, Phys. Rev. B 62, R2291 (2000).

${ }^{3} J .-$ M. Bonard, R. Gaa'1, S. Garaj, L. Thien-Nga, L. Forr'o, K. Takahashi,

F. Kokai, M. Yudasaka, and S. Iijima, J. Appl. Phys. 91, 10107 (2002).

${ }^{4}$ E. Bekyarova, K. Kaneko, D. Kasuya, K. Takahashi, F. Kokai, M. Yudasaka, and S. Iijima, Physica B 323, 143 (2002).

${ }^{5}$ C. M. Yang, H. Noguchi, K. Murata, M. Yudasaka, A. Hashimoto, S. Iijima, and K. Kaneko, Adv. Mater. (Weinheim, Ger.) 17, 866 (2005).

${ }^{6}$ K. Murata, M. Yudasaka, S. Iijima, M. El-Merraoui, and K. Kaneko, 
J. Appl. Phys. 91, 10227 (2002).

${ }^{7}$ F. Fernández-Alonso, F. J. Bermejo, C. Cabrillo, R. O. Loutfy, V. León, and M. L. Saboungi, Phys. Rev. Lett. 98, 215503 (2007).

${ }^{8}$ T. Itoh, K. Urita, E. Bekyarova, M. Arai, M. Yudasaka, S. Iijima, T. Ohba, K. Kaneko, and H. Kanoh, J. Colloid Interface Sci. 322, 209 (2008).

${ }^{9}$ J. Xu, M. Yudasaka, S. Kouraba, M. Sekido, Y. Yamamoto, and S. Iijima, Chem. Phys. Lett. 461, 189 (2008).

${ }^{10}$ S. Iijima, M. Yudasaka, R. Yamada, S. Bandow, K. Suenaga, F. Kokai, and K. Takahashi, Chem. Phys. Lett. 309, 165 (1999).

${ }^{11}$ H. Takikawa, M. Ikeda, K. Hirahara, Y. Hibi, Y. Tao, P. A. Ruiz, Jr., T. Sakakibarak, S. Itoh, and S. Iijima, Physica B 323, 277 (2002).

${ }^{12}$ M. Ikeda, H. Takikawa, T. Tahara, Y. Fujimura, M. Kato, K. Tanaka, S. Itoh, and T. Sakakibara, Jpn. J. Appl. Phys., Part 2 41, L852 (2002).

${ }^{13}$ T. Yamaguchi, S. Bandow, and S. Iijima, Chem. Phys. Lett. 389, 181 (2004).

${ }^{14}$ H. Wang, M. Chhowalla, N. Sano, S. Jia, and G. A. J. Amaratunga, Nano- technology 15, 546 (2004)

${ }^{15}$ N. Sano, J. Phys. D: Appl. Phys. 37, L17 (2004).

${ }^{16}$ N. Sano, Y. Kimura, and T. Suzuki, J. Mater. Chem. 18, 1555 (2008).

${ }^{17}$ N. Sano, Y. Yasumura, Y. Kimura, A. Toyoda, and K. Hirano, Trans. Mater. Res. Soc. Jpn. 33, 669 (2008).

${ }^{18}$ N. Sano, H. Wang, M. Chhowalla, I. Alexandrou, and G. A. J. Amaratunga, Nature (London) 414, 506 (2001).

${ }^{19}$ N. Sano, H. Wang, I. Alexandrou, M. Chhowlla, K. B. K. Teo, and G. A. J. Amaratunga, J. Appl. Phys. 92, 2783 (2002).

${ }^{20} \mathrm{P}$. Muthakarn, N. Sano, T. Charinpanitkul, W. Tanthapanichakoon, and T. Kanki, J. Phys. Chem. B 110, 18299 (2006).

${ }^{21}$ G. Baravian, Y. Chouan, A. Ricard, and G. Sultan, J. Appl. Phys. 61, 5249 (1987).

${ }^{22}$ W. Eguchi, Kagaku Kogaku Ryoron, Stoichiometry in Chemical Engineering, 2nd ed. (Kagakudojin, Tokyo, 1988), pp. 318-319. 